November - 2009

\title{
Editorial: Openness and the Future of Higher Education
}

\section{David Wiley and John Hilton III \\ Special Issue Editors}

Once considered to be mostly hype, the idea of open education has spread to hundreds of universities across the globe - including many of the world's most prestigious institutions. Open access to teaching and learning materials significantly empowers individuals who are not affiliated with formal educational programs and levels the playing field across competing institutions. These two occurrences - the empowering and leveling - portend significant changes in the structure and practice of higher education. The purpose of this special issue of IRRODL is to address various specific ways in which openness can affect the future of higher education.

In the opening article, Wiley and Hilton overview societal changes that decrease the alignment of higher education institutions with the supersystem in which they exist. Their paper argues that increasing institutional openness is a prerequisite to other critical changes required to keep higher education relevant in a quickly changing world.

The next two articles address potential barriers to the expanded use of OER and discuss how to address these barriers. Morgan and Carey explore how academic literacy in English can be a barrier to the use of many open educational resources. Their paper examines ways in which open courses can provide significant benefits to students of English as an Other Language. Lane identifies how technology and cultural barriers can impede the effective use of open educational resources. He proposes that the mediated use of open educational resources can help to reduce the diverse social and cultural digital divides within education.

Next, Baker, Thierstein, Fletcher, Kaur, and Emmons address how openness could impact the high prices of textbooks. They report how Rice University's Connexions and the Community College Open Textbook Project (CCOTP) have developed a proof-of-concept free and open textbook, and they identify lessons learned about open textbook use by students and faculty.

Two key issues relating to openness and higher education are credentialing and sustainability. Schmidt, Geith, Håklev, and Thierstein address the significant issue of the role higher education plays in providing credentials and certifications for learning. They discuss how social web technologies offer opportunities for learning, which build these skills and allow new ways to assess them. They make the case that a peer-based method of open assessment and recognition is a feasible option for accreditation purposes. 
For openness to affect higher education, it needs to be sustainable. Friesen presents the results of an informal survey of active and inactive collections of online educational resources, emphasizing data related to collection longevity and the project attributes associated with it. He shows how OER initiatives are in danger of running aground of the same sustainability challenges that have claimed numerous learning object collection or repository projects in the past.

The last two articles address how learners interact with OER. Many OER are available, including open courses. Fini examines one such course, Connectivism and Connective Knowledge (2008), facilitated by George Siemens and Stephen Downes. He looks at the the technological dimensions of the course and its impact on the participants. Ultimately, for openness to impact higher education, learners need to be willing to use OER on a large-scale basis. How do everyday learners view open courses? In the final article, Arendt and Shelton examine how residents of the state of Utah (in the United States) view the incentives and disincentives for the use of open educational resources.

Overall, this special issue presents an excellent discussion of open education issues ranging from useful descriptions of successful projects to empirical data about user attitudes to thoughtful criticisms of present work. These criticisms are particularly valuable because so much of the extant literature about open education is almost uniformly positive in tone. We hope this special issue will help to begin a more balanced discourse about the benefits and very real challenges of open education.

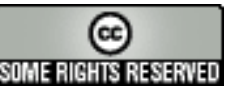

